DOI: $10.3901 / J M E .2020 .22 .120$

\title{
质子交换膜燃料电池电化学阻抗谱 弛豫时间分布研究
}

\author{
袁 浩 ${ }^{1,2}$ 戴海峰 ${ }^{1,2}$ 杜润本 ${ }^{1,2}$ 魏学哲 ${ }^{1,2}$
}

(1. 同济大学汽车学院 上海 201804;

2. 同济大学新能源工程中心 上海 201804)

摘要: 电化学阻抗谱技术能够获取燃料电池不同频率阻抗, 但对阻抗的构成缺乏进一步解析, 难以直接构建精准的等效电路 模型进行阻抗拟合分析, 而弛豫时间分布(Distribution of relaxation time, DRT)方法不需要定义特定的等效电路模型, 即可解析 燃料电池不同时间常数的极化过程。针对实验室用质子交换膜燃料电池, 在不同运行条件下对其进行阻抗谱测量, 并通过 Kramers-Kronig 关系验证所记录阻抗数据的质量。基于 DRT 分析方法, 系统地解释阻抗谱中各频段阻抗对应的物理或化学意 义。研究表明, 该电池的电化学阻抗谱主要由 3 个不同时间常数频段的极化阻抗构成, 通过与运行条件相关性的系统分析, 确定低频段阻抗为氧气在多孔介质中的传输阻碍, 中频段阻抗为与氧还原反应有关的电荷传递阻碍, 中高频段阻抗为阴极催 化剂层中的质子传输阻碍。为进一步确定 DRT 分析结果的合理性, 采用等效电路模型拟合测量的阻抗数据, 辨识的电阻元 件参数变化趋势与 DRT 分析结果一致。

关键词：质子交换膜燃料电池；电化学阻抗；极化过程；弛豫时间分布；等效电路模型

中图分类号: TM911

\section{Distribution of Relaxation Times Analysis of Proton Exchange Membrane Fuel Cell Electrochemical Impedance Spectra}

\author{
YUAN Hao $^{1,2}$ DAI Haifeng ${ }^{1,2}$ DU Runben ${ }^{1,2}$ WEI Xuezhe ${ }^{1,2}$ \\ (1. School of Automotive Studies, Tongji University, Shanghai 201804; \\ 2. National Fuel Cell Vehicle \& Powertrain System Research \& Engineering Center, \\ Tongji University, Shanghai 201804)
}

\begin{abstract}
Electrochemical impedance spectroscopy (EIS) could obtain the magnitude of fuel cell impedance at different frequencies. Still, the composition of impedance lacks further analysis, and it is challenging to reconstruct an accurate equivalent circuit model (ECM) for fitting review directly. The distribution of relaxation time (DRT) method does not need to define a specific ECM to analyze the polarization process of different time constants. For the experimental proton exchange membrane fuel cell, the EIS measurements are performed under different operating conditions, and the quality of the recorded impedance data is verified by the Kramers-Kronig relationship. Based on the DRT analysis, the physical or chemical meanings of impedance in each frequency band are systematically analyzed. The results show that the EIS is mainly composed of the polarization impedance of three different time constant frequency bands. Through analysis of the correlation with operating conditions, the low-frequency impedance is determined to be the gas diffusion barrier in the porous media, and the mid-frequency impedance is attributed to the charge transfer obstacle inside the oxygen reduction reaction, and the mid-high-frequency impedance hinders the proton transport in the cathode catalyst layer. To further determine the rationality of the DRT analysis results, an equivalent circuit model is used to fit the measured impedance data, and the changing trend of the identified resistance element parameter is consistent with the DRT analysis results.
\end{abstract}

Key words: proton exchange membrane fuel cell; electrochemical impedance spectroscopy; polarization process; distribution of relaxation time; equivalent circuit model

* 国家重点研发计划 (2017YFB0103105) 和上海市科学技术委员会 (18DZ1101103)资助项目。20200125 收到初稿, 20200827 收到修改稿 


\section{0 前言}

质子交换膜燃料电池 (Proton exchange membrane fuel cell, PEMFC)因其能量密度高、使用 效率高、环保和动态响应快等优点, 在交通运输领 域有着广泛的应用和发展前景。对于车用燃料电池 系统, 电堆的性能直接决定了整个系统工作的性能 和效率, 因此有必要研究不同外部操作条件下电池 的工作特性。目前, 通常使用极化曲线来比较燃料 电池单池的效率和性能, 但该表征方法无法辨识、 量化与性能相关的各个极化过程。

随着电信号的采集和分析技术发展成熟, 电化 学阻抗谱(Electrochemical impedance spectroscopy, EIS)测量在燃料电池领域得到了广泛的应用 ${ }^{[1]}$ 。电 化学阻抗谱能在不改变电池的工作条件下, 确定不 同工作条件(例如: 进气过量系数、电流密度、进气 湿度、进气压力、电池温度等)对电池性能的影响 ${ }^{[2]}$ 。 此外, 电化学阻抗谱可描述不同频率的极化过程, 在不同工况下测得的Nyquist 曲线可包括一个电弧 ${ }^{[3]}$ 、 两个电弧 ${ }^{[4]}$ 或明显可区分的三个电弧 ${ }^{[5]}$ 。如果两个相 邻电弧的时间常数较为接近, 则它们可能卷积成一 个电弧。在某些情况下, 可能还包含低频的感应环 路。为进一步分析阻抗的变化特征, 需要量化、分 离阻抗的不同频段过程及其对电池极化损耗的 影响。

等效电路模型(Equivalent circuit model, ECM) 是分析阻抗谱的常用方法, 该模型可描述阻抗的变 化趋势而又无需复杂的机理过程, 内部物理化学现 象可由等效电子元件替代, 单个等效电子元件值可 基于实测阻抗谱, 通过数学算法拟合得出 ${ }^{[6-9]}$ 。但是, 基于 ECM 拟合阻抗数据必须提前定义 ECM 结构, 如果对被测对象阻抗特性分析不够的话, 选择合适 的模型结构是比较困难的; 此外, 对于相同的电化 学系统, 当操作条件改变时, 可能需要不同的模型 来拟合系统的阻抗特性。

基于弛豫时间分布(Distribution of relaxation time, DRT)的分析是一种支持 ECM 开发的补充方 法, 可用于复杂电化学系统中的极化过程识别。在 DRT 分析方法中, 假设并联的电阻电容(Resistance capacitance, RC)特性占主导地位, 电化学系统可由 准无限个 $\mathrm{RC}$ 序列建模而成, 从这些 $\mathrm{RC}$ 序列中可 分解出典型的弛豫时间, 不同的电化学过程则对应 于不同的弛豫时间 ${ }^{[10]}$ 。该方法不需要定义特定的等
效电路模型, 从而将电化学系统的假设需求降至最 低 ${ }^{[11]}$ 。DRT 方法最先由德国卡尔斯鲁厄理工学院提 出, 并用于锂电池 ${ }^{[12-13]}$ 、固体氧化物燃料电池 ${ }^{[14]}$ 和 高温质子交换膜燃料电池 ${ }^{[15]}$ 研究, 清华大学的施王 影等 ${ }^{[16]}$ 也同样采用 DRT 方法和阻抗差异分析法分 析固体氧化物燃料电池的阻抗特性, 这些研究工作 表明 DRT 能够详细地解析各频段阻抗谱的极化 过程。

本文以实验室用质子交换膜燃料电池为研究对 象, 设计电化学阻抗谱测试试验, 采用 DRT 方法分 析单池阻抗特性, 确定电池内部各过程特征频率, 并利用等效电路模型拟合确定了各过程阻抗, 为之 后的燃料电池寿命衰减和故障诊断研究提供基础。

\section{1 试验和分析方法}

\section{1 试验}

本文测试对象为活性面积为 $50 \mathrm{~cm}^{2}$ 的质子交换 膜燃料电池单池, 膜电极通过燃料电池专用夹具夹 紧于石墨双极板之间, 阳极流道为深宽 $1 \mathrm{~mm}$ 的单 蛇形流道, 阴极流道为深宽 $1 \mathrm{~mm}$ 的双蛇形流道。 主要测试设备如图 1 所示, 进排气汇流排提供 99.999\%高纯氢气和清洁压缩干燥空气; 加拿大 Greenlight 的 G100 燃料电池测试台架用于燃料电池 供气和安全监测, 主要可控制参数为进气流量、进 气湿度和进气压力等; 电池温度近似为插在端板上 的加热棒温度, 温度的调节通过热电偶实时反馈控 制加热棒功率; 电池阴阳极端板两侧集流体与美国 GAMRY 电化学工作站的负载相连; 分析仪产生交 流激励并叠加至负载电流, 同时采样高频电压、电 流并计算电化学阻抗。

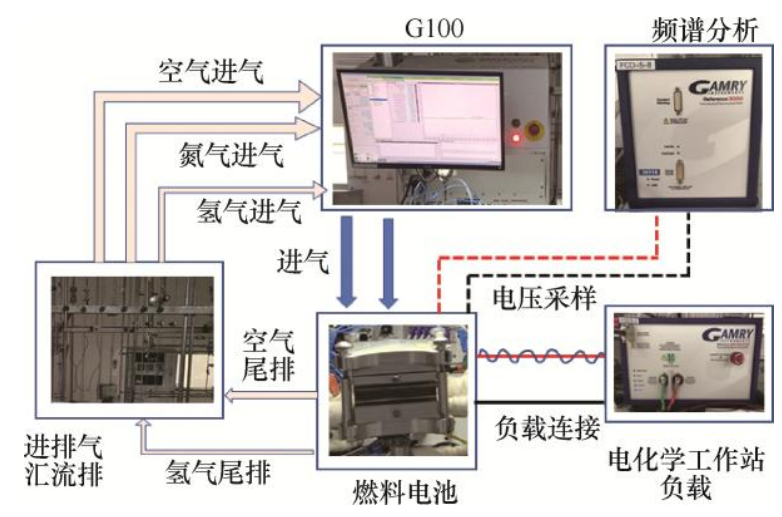

图 1 测试系统设备连接结构框图

本文主要研究阴阳极进气过量系数、进气湿度、 进气压力和电流密度等不同典型的工作条件对燃料 
电池阻抗谱的影响。在进行阻抗谱测试之前, 将电 池运行参数通过测试台架上位机调节至预设值, 稳 定运行 $20 \mathrm{~min}$, 直至电池电压稳定不变, 再进行阻 抗谱测试。为不破坏燃料电池运行的稳定性并保证 电压、电流的精确采样, 交流激励电流的幅值为直 流电流幅值的 $8 \%$, 测量频率范围为 $0.1 \mathrm{~Hz} \sim 5 \mathrm{kHz}$; 同时为了保证数据的一致性和可重复性, 所有频率 点测量 8 次并取平均值。

\section{2 分析方法}

在对阻抗谱进一步处理之前, 需要对记录数据 的质量进行检验, 常用的方法是对阻抗数据采用 Kramers-Kronig $(\mathrm{KK})$ 变换检验。阻抗数据若需要满 足因果性、线性和时不变等条件, 实部和虚部则满 足如下约束

$$
\begin{aligned}
& Z_{\mathrm{Re}}(\omega)=\frac{2}{\pi} \int_{0}^{\infty} \frac{\omega^{\prime} \cdot Z_{\mathrm{Im}}\left(\omega^{\prime}\right)}{\omega^{2}-\omega^{\prime 2}} \mathrm{~d} \omega^{\prime} \\
& Z_{\mathrm{Im}}(\omega)=-\frac{2}{\pi} \int_{0}^{\infty} \frac{\omega \cdot Z_{\mathrm{Re}}\left(\omega^{\prime}\right)}{\omega^{2}-\omega^{\prime 2}} \mathrm{~d} \omega^{\prime}
\end{aligned}
$$

式中, $Z_{\mathrm{Re}}(\omega)$ 为阻抗谱实部; $Z_{\mathrm{Im}}(\omega)$ 为阻抗谱 虚部。

由于不存在半无限积分的解析解, 因此对有效 性测试进行了修改, 使用模型(由 RC 元件串联组成) 拟合试验测量的阻抗数据。为了判断所测数据与拟 合模型的一致性, 以残差形式计算相应的偏差 ${ }^{[17]}$

$$
\begin{aligned}
\Delta \operatorname{Re}(\omega) & =\frac{Z_{\mathrm{Re}}(\omega)-\hat{Z}_{\mathrm{Re}}(\omega)}{|Z(\omega)|} \\
\Delta \operatorname{Im}(\omega) & =\frac{Z_{\mathrm{Im}}(\omega)-\hat{Z}_{\mathrm{Im}}(\omega)}{|Z(\omega)|}
\end{aligned}
$$

式中, $|Z(\omega)|$ 代表测量阻抗谱的绝对值, 如果相对 残差不超过 $1 \%$, 则认为阻抗数据满足 $\mathrm{KK}$ 关系。

DRT 分析的主要目的是辨识典型电化学阻抗谱 时间尺度的特征分布。据此, 试验测量的阻抗 $Z_{\exp }$ 在 特定频率下能够由 $Z_{\mathrm{DRT}}$ 模型拟合, $Z_{\mathrm{DRT}}$ 模型表达式 如下

$$
Z_{\mathrm{DRT}}(f)=R_{0}+R_{\mathrm{pol}}(f)=R_{0}+\int_{0}^{\infty} \frac{\gamma(\ln \tau)}{1+i 2 \pi f \tau} \mathrm{d} \ln \tau
$$

式中, $R_{0}$ 为欧姆阻抗; $R_{\mathrm{pol}}$ 为极化阻抗; $f$ 为频率; $\tau$ 为弛豫时间; $\gamma(\ln \tau)$ 为能够描述然料电池弛豫时 间特性的合适函数。

式(5)可被理解为由欧姆内阻与无限串联的 RC 元件之和的等效电路模型, 求解出弛豫时间 $\tau$ 对应 的 $\gamma(\ln \tau)$, 即可获取弛豫时间分布图。
对于测量的阻抗数据进行离散计算, 可近似为 以有限数量的弛豫时间特性 $\tau_{k}$ 为中心的狄拉克分 布 $^{[10]}$, 即 $\gamma(\ln \tau)$ 可近似为

$$
\gamma(\ln \tau)=\sum_{k=1}^{M} x_{k} \delta\left(\ln \tau-\ln \tau_{k}\right)
$$

式中, $M$ 为弛豫元件个数, 数量越多精度越高, 但 计算量也越大; $x_{k}$ 为拟合估计的未知参数, 符合狄 拉克分布。

采用式(6), 则式(5)可表示为

$$
Z_{\mathrm{DRT}}(f)=R_{0}+\sum_{k=1}^{M} \frac{x_{k}}{1+i 2 \pi f \tau_{k}}
$$

由于弛豫时间对应函数的求解涉及到不适定问 题, 需要利用正则化方法稳定求解, 以避免假峰和 较高的误差。而正则化程度由正则化参数 $\lambda$ 决定, 分布函数中的特征形状很大程度上取决于正则化参 数的值, 较大的 $\lambda$ 值会得到过于平滑的弛豫时间分 布函数, 部分阻抗信息会被过滤; 较小的 $\lambda$ 值会导 致阻抗解析过程中出现过拟合, 函数求解容易出现 震荡, 为此 $\lambda$ 的选择需要平衡拟合精度和平滑度。 常见的 $\lambda$ 选择方法有比较法、差异验证法和 $\mathrm{L}$ 曲线 法等 ${ }^{[18]}$, 文献[19]则提出了自适应正则化参数 DRT 计算方法。

目前部分学者公开了 DRT 计算相关软件或代 码, 其中香港科技大学 Ciucci 团队公开的软件 ${ }^{[20]}$ 得到了广泛应用, 本文主要研究燃料电池阻抗特性 而非 DRT 计算方法, 故采用该软件计算电池阻抗驰 豫时间分布, 正则化参数则通过比较法进行优化 选取。

\section{2 阻抗及 DRT 分析}

\section{1 阻抗谱分析}

图 2a 给出了被测电池的典型工作条件下阻抗 谱(电池温度: $75{ }^{\circ} \mathrm{C}$; 阴阳极湿度：50\%/60\%; 阴 阳极进气压力: $150 \mathrm{kPa} / 160 \mathrm{kPa}$; 阴阳极过量系数: $2 / 1.5$; 电流密度 $\left.1 \mathrm{~A} / \mathrm{cm}^{2}\right)$, 由高频直线和两个重叠 电弧组成。高频部分 $(>1.3 \mathrm{kHz})$ 的感抗特性主要与电 池连接线缆、电化学阻抗谱测试仪中的干扰等因素 有关。低频部分出现的感抗特性 $(<0.15 \mathrm{~Hz})$ 主要与杂 质吸附或中间体的形成等现象有关, 形成原因相对 复杂, 文献[21]详细综述了低频区段感抗现象的可 能原因。高频与实轴相交部分可由欧姆内阻描述, 包括电池内部电子和离子传质阻抗, 以及各组件之 间的接触阻抗, 由于电子电导率明显高于离子电导 
率, 所以欧姆损耗主要由膜电导率决定; 有文献表 明增加电池的装配转矩能够减小欧姆内阻, 这与膜 的厚度减小和接触内阻减小有关, 但接触内阻通常 比欧姆内阻小一个数量级 ${ }^{[3]}$ 。高频段电弧主要是指 Nyquist 图中在 $1000 \mathrm{~Hz}$ 或更高频率捕获的小电弧, 通常与中频段电弧发生重叠, 无法单独区分, 主要 与阳极过电势有关, 文献[22]详细讨论并验证了由 Butler-Volmer (BV) 和 Nernst 方程导出的高频电弧与 总阳极过电势之间的关系。中频段电弧表现为阴极 过电势, 反映了由电化学反应引起的电荷转移阻碍; 低频段电弧则表现为电池内部传质阻碍。

若考虑感抗效应 $L$, 则 $Z_{\mathrm{DRT}}$ 模型表达式如下

$$
Z_{\mathrm{DRT}}(f)=R_{0}+i 2 \pi f L+\sum_{k=1}^{M} \frac{x_{k}}{1+i 2 \pi f \tau_{k}}
$$

该阻抗谱弛豫时间分布如图 $2 b$ 所示, 其中实线 为不考虑感抗作用的 DRT 分析, 具有三个不同形状 的波形 $P_{1} 、 P_{2}$ 和 $P_{3}$, 分别在低频段 $10 \mathrm{~Hz}$ 、中频段 $150 \mathrm{~Hz}$ 和中高频段 $730 \mathrm{~Hz}$ 附近出现波峰。虚线为考 虑感抗作用的 DRT 分析, 与不考虑感抗作用相比, 高频额外解析出波峰 $P_{4}$; 由于低频阻抗只测量至 0.1 $\mathrm{Hz}$, 没有出现与低频感抗有关的波峰; 此外, 考虑 到高频感抗主要与测量噪声和设备干扰有关, 与电 池内部极化过程耦合性较弱, 且该感抗作用轻微影 响波形 $P_{3}$, 不影响中低频段的波形, 因此本文忽略 频谱中的感抗特性。总之, 与 Nyquist 曲线相比, DRT 分析可将燃料电池阻抗谱以不同时间尺度的波 形清晰显示。

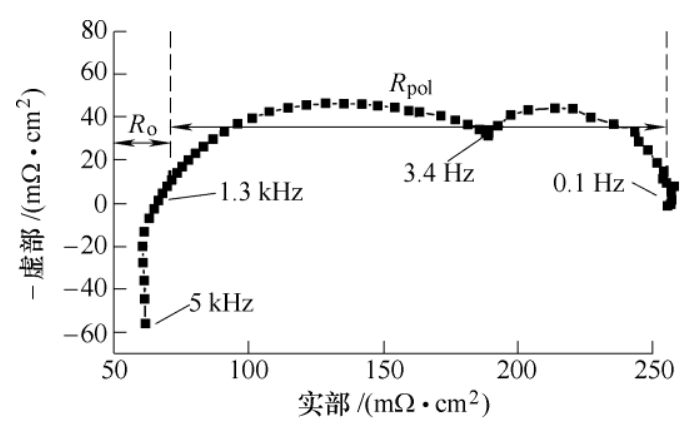

(a) 典型工况阻抗谱测试结果

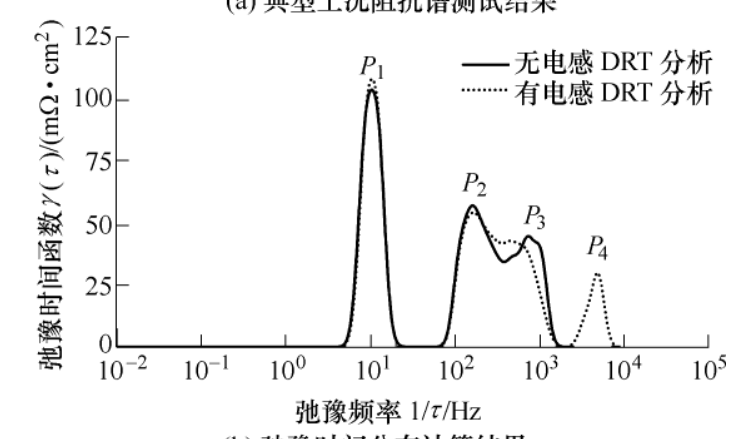

(b) 弛豫时间分布计算结果

图 2 典型工况阻抗谱及其 DRT 计算
为了验证忽略感抗数据的可靠性, 采用 $\mathrm{KK}$ 变换 对其进行检验。该阻抗谱的测量值和 KK 拟合值如图 3 所示, 可看出拟合度较高, 实部最大残差为 $0.95 \%$, 虚 部最大残差为 $0.47 \%$, 且绝大多数阻抗的残差都在 $0.5 \%$ 以内, 认为该测量阻抗数据满足 $\mathrm{KK}$ 关系。基于此检 验方法, 本文使用的阻抗数据均满足 $\mathrm{KK}$ 关系。

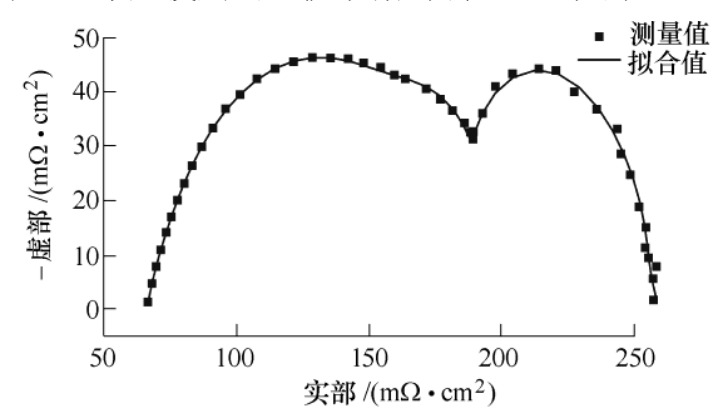

(a) EIS 数据及其 $\mathrm{KK}$ 重构

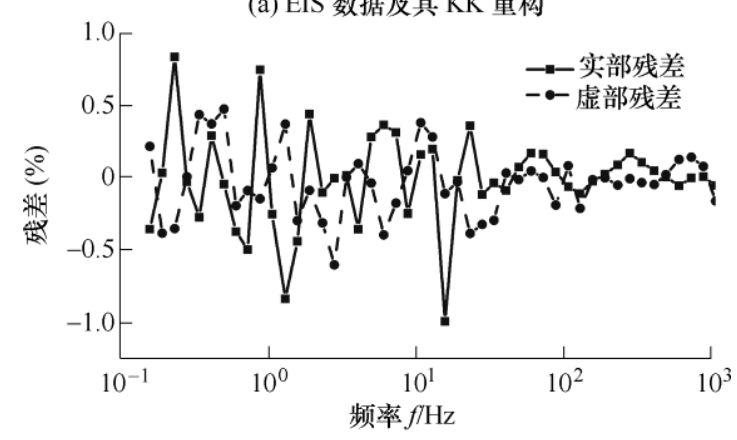

(b) 重构残差

图 3 典型工况下电化学阻抗 $\mathrm{KK}$ 变换

如前所述, 弛豫时间分布的波峰数量和形状依 赖于正则化参数 $\lambda$ 的选取。图 4 显示了正则化参数 从 $10^{-1}$ 变化至 $10^{-4}$ 的 DRT 计算结果, 可以看出, 较 小的 $\lambda$ 值会导致较高的波峰, 且波形较窄; 较大的 $\lambda$ 值会导致较低的波峰, 且无法解析部分时间尺度。 考虑到较小的 $\lambda$ 值可能会引入较大误差振荡, 较大 的 $\lambda$ 无法解析部分时间尺度, 因此根据比较结果以 及文献[15-16]使用的 $\lambda$ 值, 本文所有 DRT 计算采用 的 $\lambda$ 值均为 $1 \times 10^{-3}$ 。
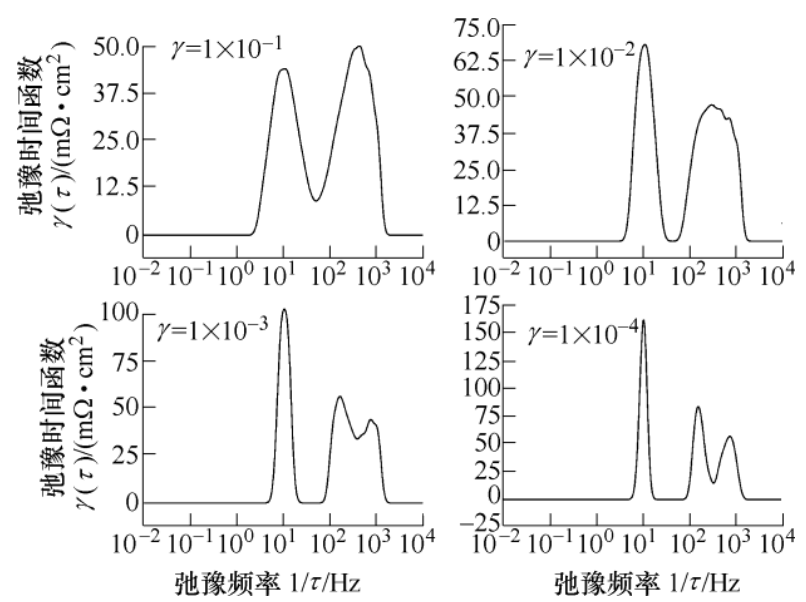

图 4 同一阻抗谱下不同正则化参数 DRT 结果 


\section{2 进气过量系数}

\subsection{1 不同阴极进气过量系数影响分析}

在燃料电池系统中, 阴极进气流量主要由空压 机和背压阀协同控制, 较低的过量系数容易引发燃 料电池饥饿现象, 过大的过量系数会导致系统寄生 功率过高, 同时容易出现膜干现象。为研究阴极进 气过量系数对燃料电池阻抗谱的影响, 依次改变空 气过量系数为 $1.5 、 1.7 、 2 、 2.5$ 和 3.0 , 其他运行参 数保持不变, 待电池性能稳定后, 进行阻抗测试, 主要运行参数如表 1 所示。

\section{表 1 不同阴极进气过量系数下阻抗测试条件}

\begin{tabular}{ccccc}
\hline $\begin{array}{c}\text { 阴阳极 } \\
\text { 湿度 }(\%)\end{array}$ & $\begin{array}{c}\text { 阴阳极 } \\
\text { 压力 } / \mathrm{kPa}\end{array}$ & $\begin{array}{c}\text { 阴阳极过量 } \\
\text { 系数 }\end{array}$ & $\begin{array}{c}\text { 电流密度 } \\
/\left(\mathrm{A} / \mathrm{cm}^{2}\right)\end{array}$ & $\begin{array}{c}\text { 电池温度 } \\
/{ }^{\circ} \mathrm{C}\end{array}$ \\
\hline $50 / 60$ & $150 / 160$ & $1.5 / 1.5$ & 1 & 75 \\
$50 / 60$ & $150 / 160$ & $1.7 / 1.5$ & 1 & 75 \\
$50 / 60$ & $150 / 160$ & $2.0 / 1.5$ & 1 & 75 \\
$50 / 60$ & $150 / 160$ & $2.5 / 1.5$ & 1 & 75 \\
$50 / 60$ & $150 / 160$ & $3.0 / 1.5$ & 1 & 75 \\
\hline
\end{tabular}

如图 5a 所示, 阴极进气过量系数对电池阻抗谱 具有明显的影响。随着过量系数的降低, 两个重叠 电弧的直径明显增大, 尤其是低频处电弧。图 $5 \mathrm{~b}$ 展示了不同阴极进气过量系数下的 DRT 分析结果, 主要由波形 $P_{1} 、 P_{2}$ 和 $P_{3}$ 组成。随着阴极进气过量系 数增加, $P_{1}$ 的波峰和频率逐渐减小, 与低频处的阻抗 谱对应, 可能与阴极侧多孔介质内传输过程有关。 供气流量较高时, 阴极侧流道内氧气平均浓度较高,
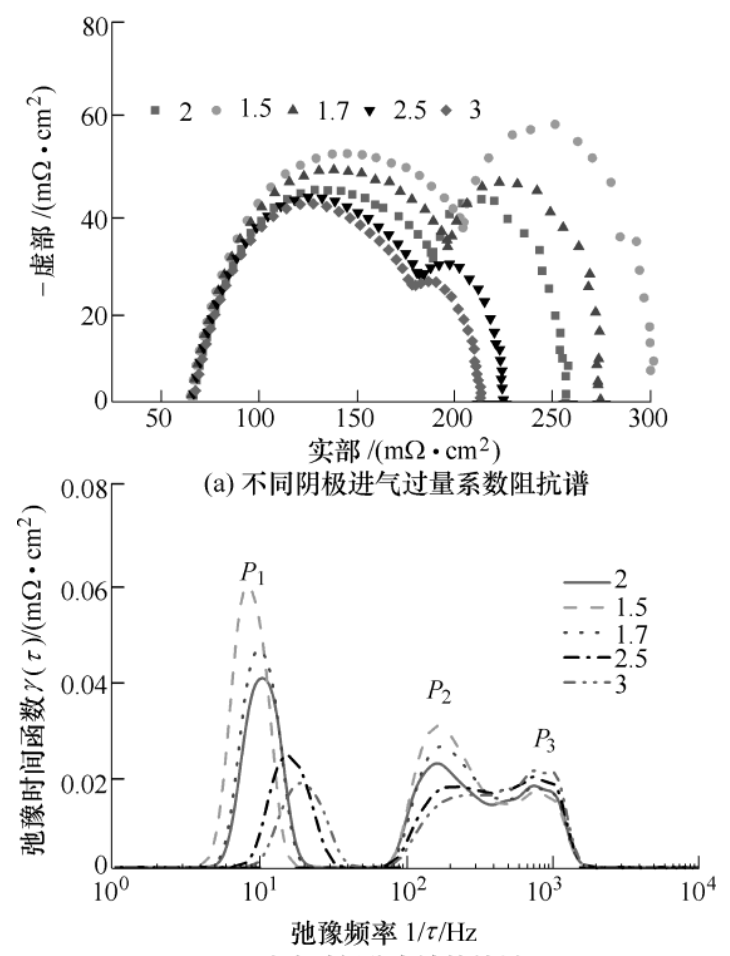

(b) 弛豫时间分布计算结果

图 5 不同阴极进气过量系数下阻抗测试分析结果
从而减缓了多孔介质内的传质损耗; 然而, 过量系 数从 2.5 到 3.0 转变时, $P_{1}$ 的波峰下降幅度相对较 小, 这表明过量系数在 2.5 时, 催化剂层表面已经 附着了相当数量的氧气分子, 此时进一步增加过量 系数, 不能显著减小氧气传输限制。文献[15]采用 纯氧气代替空气进行阻抗谱测试并利用 DRT 方法 分析, $P_{1}$ 波形几乎消失，同样表明 $P_{1}$ 波形可能与氧 气扩散过程有关。低频阻抗除了与反应气体传质有 关, 有文献表明还与膜内水扩散难易程度有关 ${ }^{[4]}$, 主 要由膜内水扩散系数决定, 可根据高频欧姆内阻 $R_{\mathrm{ohm}}$ 、电导率 $\sigma$ 以及膜的厚度 $L$ 计算, 主要公式如下

$$
\begin{gathered}
R_{\mathrm{ohm}}=\frac{L}{100 \cdot A \sigma} \\
\sigma=\left(0.5193 \lambda_{\mathrm{m}}-0.326\right) \exp \left[1268\left(\frac{1}{303}-\frac{1}{T}\right)\right] \\
D_{\mathrm{w}}=D_{\lambda} \exp \left[2416\left(\frac{1}{303}-\frac{1}{T}\right)\right]
\end{gathered}
$$

$$
D_{\lambda}= \begin{cases}10^{-6} & 0<\lambda_{\mathrm{m}}<2 \\ 10^{-6}\left(2 \lambda_{\mathrm{m}}-3\right) & 2 \leqslant \lambda_{\mathrm{m}}<3 \\ 10^{-6}\left(3-1.67\left(\lambda_{\mathrm{m}}-3\right)\right) & 3.0 \leqslant \lambda_{\mathrm{m}}<4.5 \\ 1.25 \times 10^{-6} & \lambda_{\mathrm{m}} \geqslant 4.5\end{cases}
$$

式中, $A$ 为有效活性面积; $\lambda_{\mathrm{m}}$ 为膜含水量; $D_{\lambda}$ 为 $30{ }^{\circ} \mathrm{C}$ 时膜内水传质系数; $D_{\mathrm{w}}$ 为基于温度修正后的 膜内水传质系数。

当过量系数从 1.5 变为 3.0 时, 欧姆内阻从 $1.38 \mathrm{~m} \Omega$ 变为 $1.43 \mathrm{~m} \Omega$, 膜内水浓差扩散系数由 $4.33 \times 10^{-6}$ 变为 $4.86 \times 10^{-6}$, 从而对应 $P_{1}$ 波峰下降。

$P_{2}$ 对阴极进气过量系数变化也较为敏感, 这可 能与阴极催化剂层内氧气还原反应有关, 氧气还原 反应的电荷传递特性可由 BV 方程描述

$$
j=j_{0}(\exp (\alpha n F \eta /(R T))-\exp (-(1-\alpha) n F \eta /(R T)))
$$

式中, $j$ 为电流密度; $j_{0}$ 代表交换电流密度; $\alpha$ 称 为传输系数, 取决于活化能垒的对称性; $n$ 为化学 反应电子转移数; $\eta$ 为电压损失; $F 、 R$ 和 $T$ 分别为 法拉第常数、气体常数和反应温度。

利用 BV 曲线在对应电流密度处的反斜率，由 化学反应动力学引起的传荷阻抗

$$
R_{\mathrm{ct}}=\frac{\partial \eta}{\partial j}
$$

在电池温度和传输系数一定的条件下, 为减小 传荷阻抗, 有必要增大交换电流密度, 而交换电流 密度可表示为 


$$
j_{0}=n F c_{\mathrm{R}}^{*} f_{1} \exp (-\Delta G /(R T))
$$

式中, $c_{\mathrm{R}}^{*}$ 为催化剂层三相界面处的反应物浓度; $G$ 为活化能垒。

在只改变电池运行条件的前提下, 较高的阴极 进气过量系数能够提高反应物浓度或内部气体分 压, 进而交换电流密度增加, 传荷内阻减小, 所以 对应于 $P_{2}$ 的波峰减小。此外, 文献[15]利用纯氢气 代替阴极的空气供给, 对其进行阻抗谱测量和 DRT 分析, 结果表明低频的 $P_{1}$ 和中频的 $P_{2}(30 \mathrm{~Hz}) 、 P_{3}$ $(50 \mathrm{~Hz})$ 都几乎消失, 一方面进一步证明了低频处波 形与氧气扩散过程有关, 另一方面说明了中频段波 形主要与氧气还原反应有关。

空气过量系数对中高频处的 $P_{3}$ 影响相对较小, $P_{3}$ 的波峰随着过量系数增加而略有上升, 可能与阴 极侧质子传输过程有关。较大的进气过量系数会带 走更多的气态水或液态水, 导致交换膜和催化剂层 内膜结合水含量下降, 阴极处质子传输限制增加, 从而对应于 $P_{3}$ 波峰增加, 所以欧姆内阻也具有增加 趋势。

\subsection{2 不同阳极进气过量系数影响分析}

与氧饥饿相比, 氢饥饿更容易引起电池反极, 为此同样需要研究不同阳极进气过量系数对燃料电 池阻抗谱的影响。依次改变氢气过量系数为 1.2 、 1.4、 1.8 和 2.0 , 其他运行参数不变, 待电池性能稳 定后, 进行阻抗测试, 主要运行参数如表 2 所示。

\section{表 2 不同阳极进气过量系数下阻抗测试条件}

\begin{tabular}{ccccc}
\hline $\begin{array}{c}\text { 阴阳极 } \\
\text { 湿度 }(\%)\end{array}$ & $\begin{array}{c}\text { 阴阳极 } \\
\text { 压力 } / \mathrm{kPa}\end{array}$ & $\begin{array}{c}\text { 阴阳极过量 } \\
\text { 系数 }\end{array}$ & $\begin{array}{c}\text { 电流密度 } \\
/\left(\mathrm{A} / \mathrm{cm}^{2}\right)\end{array}$ & $\begin{array}{c}\text { 电池温度 } \\
/{ }^{\circ} \mathrm{C}\end{array}$ \\
\hline $50 / 60$ & $150 / 160$ & $2 / 1.2$ & 1 & 75 \\
$50 / 60$ & $150 / 160$ & $2 / 1.4$ & 1 & 75 \\
$50 / 60$ & $150 / 160$ & $2 / 1.8$ & 1 & 75 \\
$50 / 60$ & $150 / 160$ & $2 / 2$ & 1 & 75 \\
\hline
\end{tabular}

阻抗谱及其 DRT 分析结果如图 6 所示, 阻抗谱 电弧半径及重叠关系未出现明显变化, 所有波形的 频率和幅值变化范围也较小, 这也进一步说明了前 面 DRT 分析结果的合理性, 表明 $P_{1} 、 P_{2}$ 和 $P_{3}$ 波形 主要与阴极内部过程有关。针对该电池, 阳极过程 的波形未能解析, 可能是测试过程中阳极进气压力 一直保持在 $160 \mathrm{kPa}$, 且试验用的氢气纯度较高, 因 此改变氢气过量系数不能显著改变阳极腔体内部氢 气压力或浓度, 进而无法进一步改变反应动力学的 电荷转移过程; 此外, 氢气的氧化反应动力学极其 迅速, 而氧气的还原动力学较为缓慢, 因此活化损 耗主要发生在阴极, 即阳极反应阻抗在电池总阻抗
中起次要作用。另外, 可能是频率达到 $1.3 \mathrm{kHz}$ 时, 该电池出现感抗特性, 高频的阳极过程与感抗特性混 合而被忽略了。

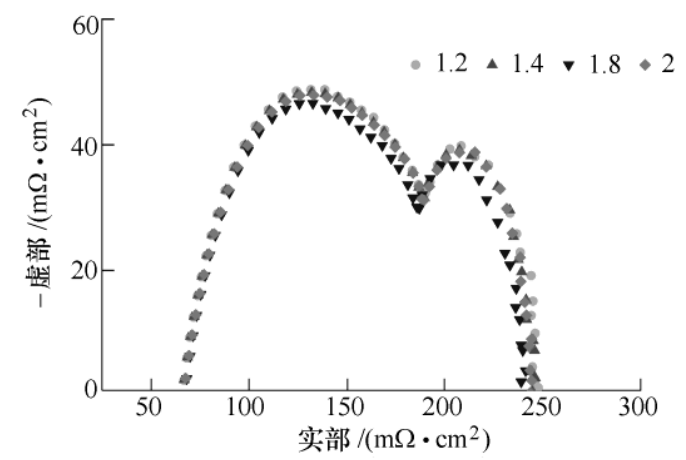

(a) 不同阳极进气过量系数阻抗谱

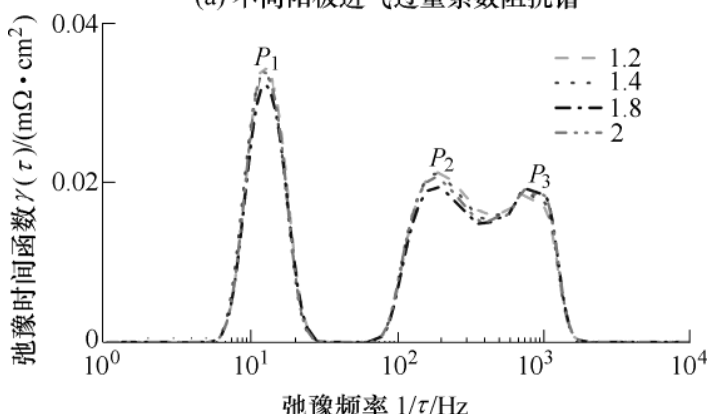

(b) 弛豫时间分布计算结果

图 6 不同阳极进气过量系数下阻抗测试分析结果

综上, 由于阳极进气过量系数对阻抗谱的影响 相对较小, 且阳极进气比例阀的控制响应速度较快, 所以目前车用氢气供给系统通常以进气压力为反馈 控制目标。

\section{3 电流密度}

为研究电流密度对燃料电池阻抗谱影响, 分别 改变电流密度为 $1.0 \mathrm{~A} / \mathrm{cm}^{2} 、 1.2 \mathrm{~A} / \mathrm{cm}^{2} 、 1.4 \mathrm{~A} / \mathrm{cm}^{2}$ 、 $1.8 \mathrm{~A} / \mathrm{cm}^{2} 、 2.0 \mathrm{~A} / \mathrm{cm}^{2}$, 保持其他参数不变, 待电池性 能稳定后, 进行阻抗测试, 主要运行参数如表 3 所示。

表 3 不同电流密度下阻抗测试条件

\begin{tabular}{ccccc}
\hline $\begin{array}{c}\text { 阴阳极 } \\
\text { 湿度 }(\%)\end{array}$ & $\begin{array}{c}\text { 阴阳极 } \\
\text { 压力/kPa }\end{array}$ & $\begin{array}{c}\text { 阴阳极过量 } \\
\text { 系数 }\end{array}$ & $\begin{array}{c}\text { 电流密度/ } \\
\left(\mathrm{A} / \mathrm{cm}^{2}\right)\end{array}$ & $\begin{array}{c}\text { 电池温度/ } \\
{ }^{\circ} \mathrm{C}\end{array}$ \\
\hline $50 / 60$ & $150 / 160$ & $2 / 1.5$ & 1 & 75 \\
$50 / 60$ & $150 / 160$ & $2 / 1.5$ & 1.2 & 75 \\
$50 / 60$ & $150 / 160$ & $2 / 1.5$ & 1.4 & 75 \\
$50 / 60$ & $150 / 160$ & $2 / 1.5$ & 1.8 & 75 \\
$50 / 60$ & $150 / 160$ & $2 / 1.5$ & 2 & 75 \\
\hline
\end{tabular}

如图 7 所示, 随着电流密度增加, 中低频段电 弧半径明显增大, 弛豫时间分布也能够更直观地显 示阻抗变化趋势。其中, $P_{1}$ 的波峰随着电流密度增 加而明显增大, 表明质量传输限制明显, 这是因为 在该范围的电流密度下反应生成水较多, 多孔介质 
和流道内容易形成冷凝水, 有效孔隙率下降, 从而 阻碍内部反应气体传输过程。

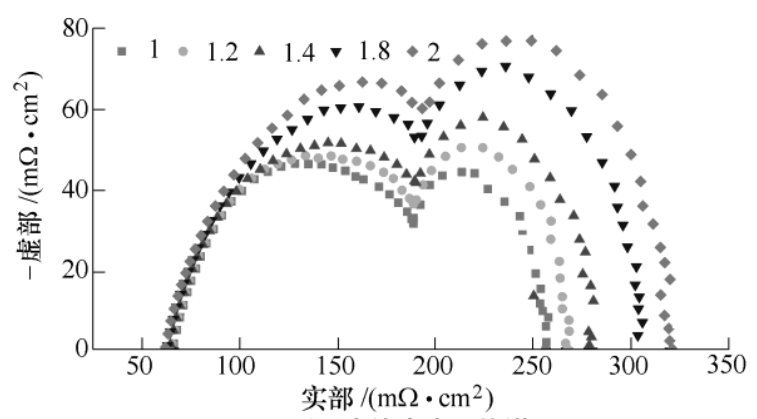

(a) 不同电流密度阻抗谱

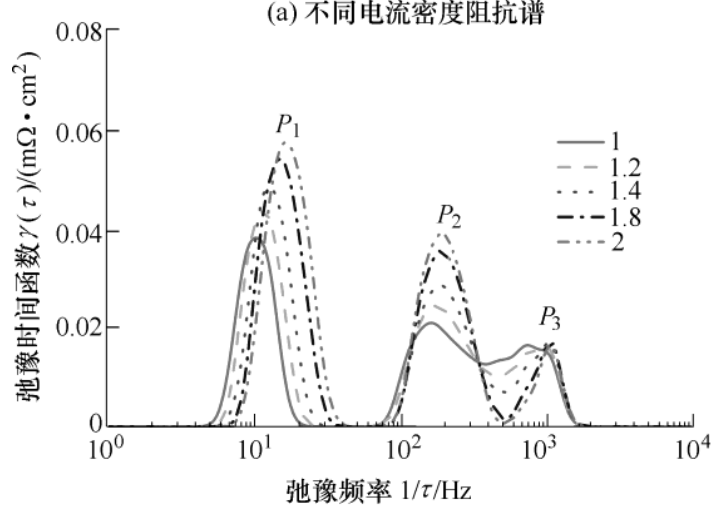

(b) 弛豫时间分布计算结果

图 7 不同电流密度下阻抗测试分析结果

$P_{2}$ 主要与氧还原反应有关, 虽然大电流密度会 驱使发生电化学反应, 但在进气过量系数和压力一 定的条件下，电流密度如果超过特定范围，催化剂 层内反应物浓度会逐渐降低, 而生成水逐渐增多, 甚至高于流道内氧气浓度, 反应损耗将会增加; 在 该电流密度区段, 浓差引起的反应损耗高于反应驱 使作用, 因此 $P_{2}$ 的波峰也会增加; 这也与极化曲线 测量结果一致, 当电流密度大于 $1.2 \mathrm{~A} / \mathrm{cm}^{2}$ 时, 极化 曲线进入浓差损耗区段。

$P_{3}$ 的波峰几乎保持不变, 但波形的宽度随着电流 密度增加而减小, 表明质子传输阻碍有减小趋势, 主要与阴极侧交换膜和催化剂层内的膜结合水含量 增加有关, 欧姆内阻也略微下降, 从起初的 $1.41 \mathrm{~m} \Omega$ $\left(1 \mathrm{~A} / \mathrm{cm}^{2}\right)$ 减小为 $1.32 \mathrm{~m} \Omega\left(2 \mathrm{~A} / \mathrm{cm}^{2}\right)$, 膜内水扩散系数 从 $4.65 \times 10^{-6}$ 变为 $3.64 \times 10^{-6}$, 传质阻碍增大。

\section{4 进气湿度}

\subsection{1 不同阴极进气湿度影响分析}

阴极进气相对湿度对于燃料电池的稳定运行 和输出功率具有重要影响, 为研究阴极进气湿度 对阻抗谱的影响, 依次改变阴极进气相对湿度为 $20 \% 、 40 \% 、 80 \%$ 和 $90 \%$; 相对湿度不低于 $20 \%$ 是为了防止膜干故障, 相对湿度不高于 $90 \%$ 是为 了降低水淹的风险, 其他运行参数不变, 待电池 性能稳定后, 进行阻抗测试, 主要运行参数如
表 4 所示。

表 4 不同阴极进气湿度下阻抗测试条件

\begin{tabular}{ccccc}
\hline $\begin{array}{c}\text { 阴阳极 } \\
\text { 湿度 }(\%)\end{array}$ & $\begin{array}{c}\text { 阴阳极 } \\
\text { 压力 } / \mathrm{kPa}\end{array}$ & $\begin{array}{c}\text { 阴阳极过量 } \\
\text { 系数 }\end{array}$ & $\begin{array}{c}\text { 电流密度 } \\
/\left(\mathrm{A} / \mathrm{cm}^{2}\right)\end{array}$ & $\begin{array}{c}\text { 电池温度 } \\
/{ }^{\circ} \mathrm{C}\end{array}$ \\
\hline $20 / 60$ & $150 / 160$ & $2 / 1.5$ & 1 & 75 \\
$40 / 60$ & $150 / 160$ & $2 / 1.5$ & 1 & 75 \\
$80 / 60$ & $150 / 160$ & $2 / 1.5$ & 1 & 75 \\
$90 / 60$ & $150 / 160$ & $2 / 1.5$ & 1 & 75 \\
\hline
\end{tabular}

阻抗谱测试和 DRT 分析结果如图 8 所示, 其中, $P_{3}$ 对湿度变化也较为敏感, 湿度从 $20 \%$ 变为 $90 \%$ 时, 波峰下降明显，波形宽度也明显减小，电池的欧姆 内阻也从 $1.41 \mathrm{~m} \Omega(20 \%)$ 变为 $1.29 \mathrm{~m} \Omega(90 \%)$, 这也进 一步说明了 $P_{3}$ 主要与质子传输过程有关。 $P_{1}$ 的波峰 也稍有下降，表明质量传输阻碍得到了一定减小， 这可能是在该电流密度下, 电池内部未发生水淹, 而进气湿度的不同则改变了多孔介质内的 $\mathrm{O}_{2} / \mathrm{N}_{2} / \mathrm{H}$ 的比例, 影响物质传输的有效扩散系 数, 进而改变了反应气体质量传输效率; 但是, 膜 内水的浓差扩散系数从 $4.65 \times 10^{-6}$ 变为 $3.27 \times 10^{-6}$, 膜内传质阻碍增大, 表明与膜内浓差扩散机制相比, 氧气扩散传输在低频段 $P_{1}$ 中占据主导地位。 $P_{2}$ 对湿 度变化不敏感，但受质子传递过程影响，波峰略有 下降, 整体电荷转移动力学过程影响较小。综上, 在电池内部不发生水淹的前提下，提高阴极进气湿 度可降低电池内阻。

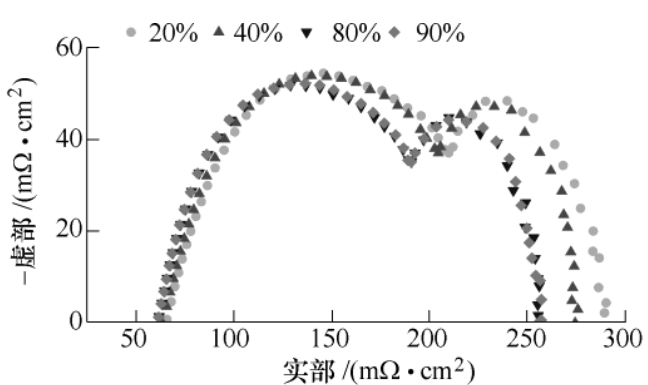

(a) 不同阴极进气湿度阻抗谱

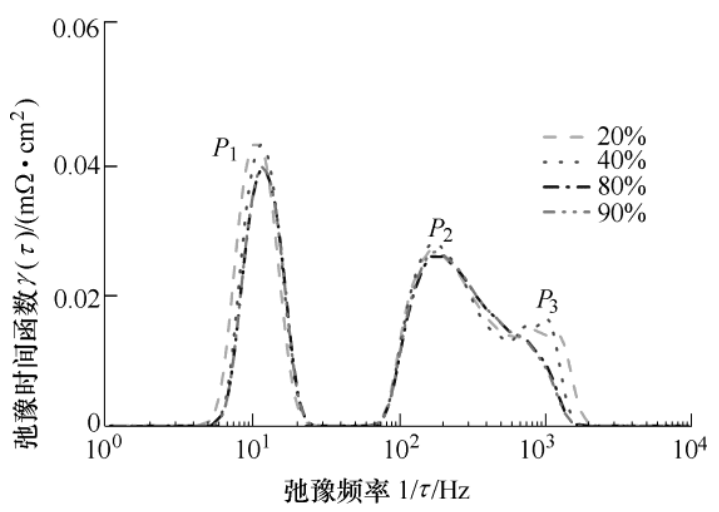

(b) 弛豫时间分布计算结果

图 8 不同阴极进气湿度下阻抗测试分析结果 


\subsection{2 不同阳极进气湿度影响分析}

为研究阳极进气湿度对阻抗谱的影响, 依次改 变阳极进气相对湿度为 $20 \% 、 40 \%$ 和 $80 \%$, 保持其 他参数不变, 待电池性能稳定后, 进行阻抗测试, 主要测试条件如表 5 所示。

表 5 不同阳极进气湿度下阻抗测试条件

\begin{tabular}{ccccc}
\hline $\begin{array}{c}\text { 阴阳极 } \\
\text { 湿度 }(\%)\end{array}$ & $\begin{array}{c}\text { 阴阳极 } \\
\text { 压力 } / \mathrm{kPa}\end{array}$ & $\begin{array}{c}\text { 阴阳极过量 } \\
\text { 系数 }\end{array}$ & $\begin{array}{c}\text { 电流密度/ } \\
\left(\mathrm{A} / \mathrm{cm}^{2}\right)\end{array}$ & $\begin{array}{c}\text { 电池温度/ } \\
{ }^{\circ} \mathrm{C}\end{array}$ \\
\hline $50 / 20$ & $150 / 160$ & $2 / 1.5$ & 1 & 75 \\
$50 / 40$ & $150 / 160$ & $2 / 1.5$ & 1 & 75 \\
$50 / 80$ & $150 / 160$ & $2 / 1.5$ & 1 & 75 \\
\hline
\end{tabular}

图 9 展示了不同阳极相对湿度下阻抗谱测试和 DRT 分析结果, 可以看出阳极相对湿度对阻抗谱的 影响较小, 所有波形变化均不明显, 表明阳极湿度 对阴极侧极化过程影响不大。随着阳极进气湿度增 加, 欧姆内阻和传荷内阻稍有下降, 质子传递阻抗 几乎不变, 质量传输阻抗整体也不变, 也进一步说 明了 $P_{1} 、 P_{2}$ 和 $P_{3}$ 主要受到阴极极化过程影响。因 此, 目前车用燃料电池系统阳极侧通常不配备加湿 器, 利用浓差扩散机制驱动阴极膜侧水对阳极侧腔 体内部气体加湿。

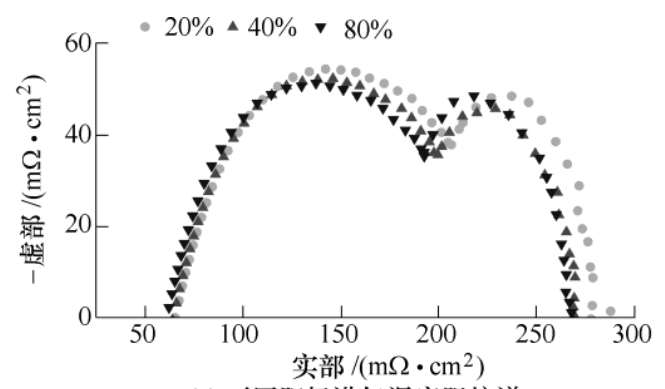

(a) 不同阳极进气湿度阻抗谱

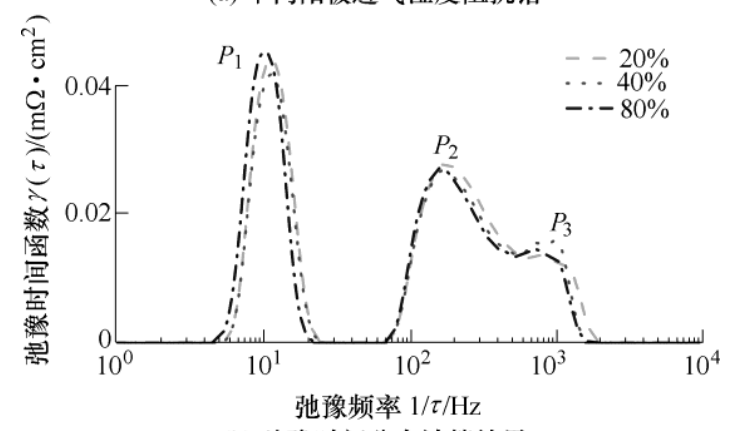

(b) 弛豫时间分布计算结果

图 9 不同阳极进气湿度下阻抗测试分析结果

\section{5 进气压力}

进气压力是车用燃料电池系统控制的关键参 数, 为研究进气压力对阻抗谱的影响, 同时防止 膜两侧压差过大对电池造成不可逆损伤, 需要保 持阴阳极进气压力差在一定范围内; 依次分别改
变阴阳极的两侧压力为 $60 / 70 \mathrm{kPa} 、 90 / 100 \mathrm{kPa}$ 、 $120 / 130 \mathrm{kPa}$ 和 $170 / 180 \mathrm{kPa}$, 保持其他参数不变, 待电池性能稳定后, 进行阻抗测试, 主要测试条 件如表 6 所示。

表 6 不同进气压力下阻抗测试条件

\begin{tabular}{ccccc}
\hline $\begin{array}{c}\text { 阴阳极 } \\
\text { 湿度 }(\%)\end{array}$ & $\begin{array}{c}\text { 阴阳极 } \\
\text { 压力 } / \mathrm{kPa}\end{array}$ & $\begin{array}{c}\text { 阴阳极过量 } \\
\text { 系数 }\end{array}$ & $\begin{array}{c}\text { 电流密度/ } \\
\left(\mathrm{A} / \mathrm{cm}^{2}\right)\end{array}$ & $\begin{array}{c}\text { 电池温度/ } \\
{ }^{\circ} \mathrm{C}\end{array}$ \\
\hline $50 / 60$ & $60 / 70$ & $2 / 1.5$ & 1 & 75 \\
$50 / 60$ & $90 / 100$ & $2 / 1.5$ & 1 & 75 \\
$50 / 60$ & $120 / 130$ & $2 / 1.5$ & 1 & 75 \\
$50 / 60$ & $170 / 180$ & $2 / 1.5$ & 1 & 75 \\
\hline
\end{tabular}

不同进气压力对阻抗谱的影响如图 10 所示, 可 以看出阻抗谱的变化对进气压力较为敏感，阻抗谱 两个圆弧半径变化明显。在进气过量系数和电池温 度一定条件下, 进气压力越大, 流道进出口压差驱 动流体流动, 从而改善流道内部的对流传质作用; 此外, 电池内部各气体分压也会上升, 进而多孔介 质内部对流作用增加, 有利于克服多孔介质内的黏 附效应, 改善质量传输, 进而 $P_{1}$ 和 $P_{2}$ 波峰明显减 小。 $P_{3}$ 的波峰虽然整体变化趋势不明显, 但波形宽 度随着压力增大而增大, 这可能与高频欧姆内阻变 化有关。

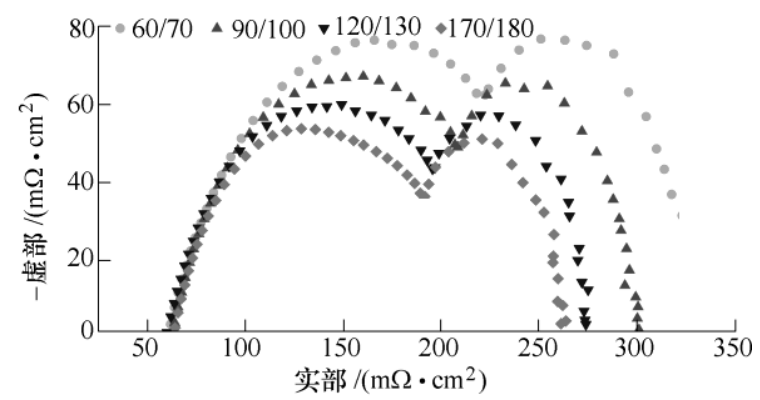

(a) 典型工况阻抗谱测试结果

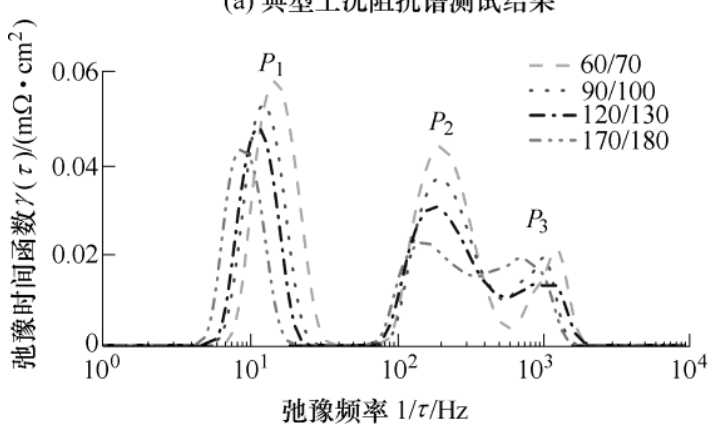

(b) 弛豫时间分布计算结果

图 10 不同进气压力下阻抗测试分析结果

\section{3 等效电路建模}

如上所述, 该试验用质子交换膜燃料电池主要 
在 $10 \mathrm{~Hz} 、 150 \mathrm{~Hz}$ 和 $730 \mathrm{~Hz}$ 的频段内出现 3 个特征 波形, 为进一步验证上述 DRT 分析的合理性并确定 各极化过程对应的阻抗大小, 采用等效电路模型的 方法拟合阻抗谱数据。

由于许多等效电路会导致相似的阻抗响应, 需要合理选择电子元件。由于该电池阻抗弧线并 非完整的半圆, 电极和膜界面之间并非均匀分布 的双层电容。等效电路模型选用的基础元件为纯 电阻和 $\mathrm{RQ}$ 并联电路。其中常相位元件 $\mathrm{Q}$ 的阻抗 计算公式为

$$
Z_{Q}=\frac{1}{T_{Q}(j \omega)^{\varphi}}
$$

式中, $T_{Q}$ 为特征常数, $\omega$ 为角频率; 当 $\varphi=0$ 时, $Z_{Q}$ 具有纯电阻特性, 当 $\varphi=1$ 时, $Z_{Q}$ 具有纯电容特性。

在典型工作条件下，分别采用二阶、三阶和四 阶等效电路模型去拟合阻抗, 拟合结果的卡方值分 别为 $5.86 \times 10^{-3}, 1.87 \times 10^{-3}$ 和 $1.85 \times 10^{-3}$ 。三阶和四阶 等效电路模型的拟合结果均具有较高可信度，但与 三阶模型相比，四阶模型拟合精度没有明显提升。 此外, 根据 DRT 分析结果, 该燃料电池阻抗主要由 3 个极化特征过程组成。据此, 等效电路模型选用 的基础元件为纯电阻和 3 个 $\mathrm{RQ}$ 并联电路。

不同阴极进气过量系数下阻抗拟合如图 11 所 示，基于该模型不同运行条件下各频段阻抗的拟合 结果如图 12 所示。其中, 阴极运行条件对内部阻抗 影响较大，阳极条件影响相对较小，同样表明各阻 抗主要与阴极内部过程有关, 与 $P_{1} 、 P_{2}$ 和 $P_{3}$ 一致。 此外, 对于该电池, 在电流密度为 $1 \mathrm{~A} / \mathrm{cm}^{2}$ (额定功 率点附近)时, 大部分运行条件下质量传输阻抗占据 主导地位。

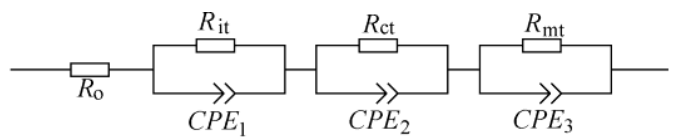

(a) 等效电路模型

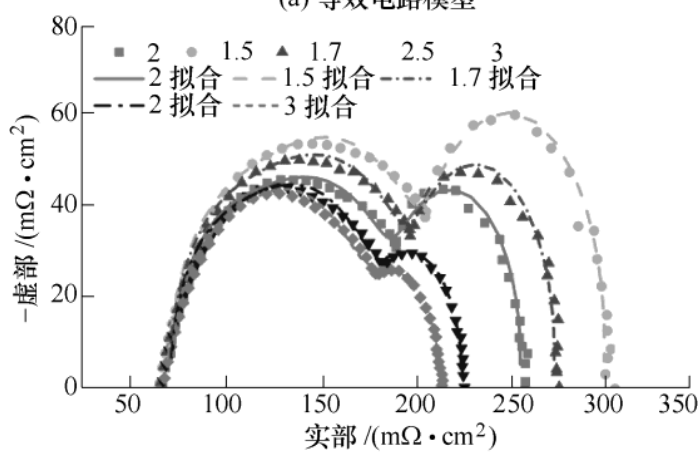

(b) 等效电路模型拟合

图 11 等效电路模型及不同阴极进气过量系数下阻抗拟合
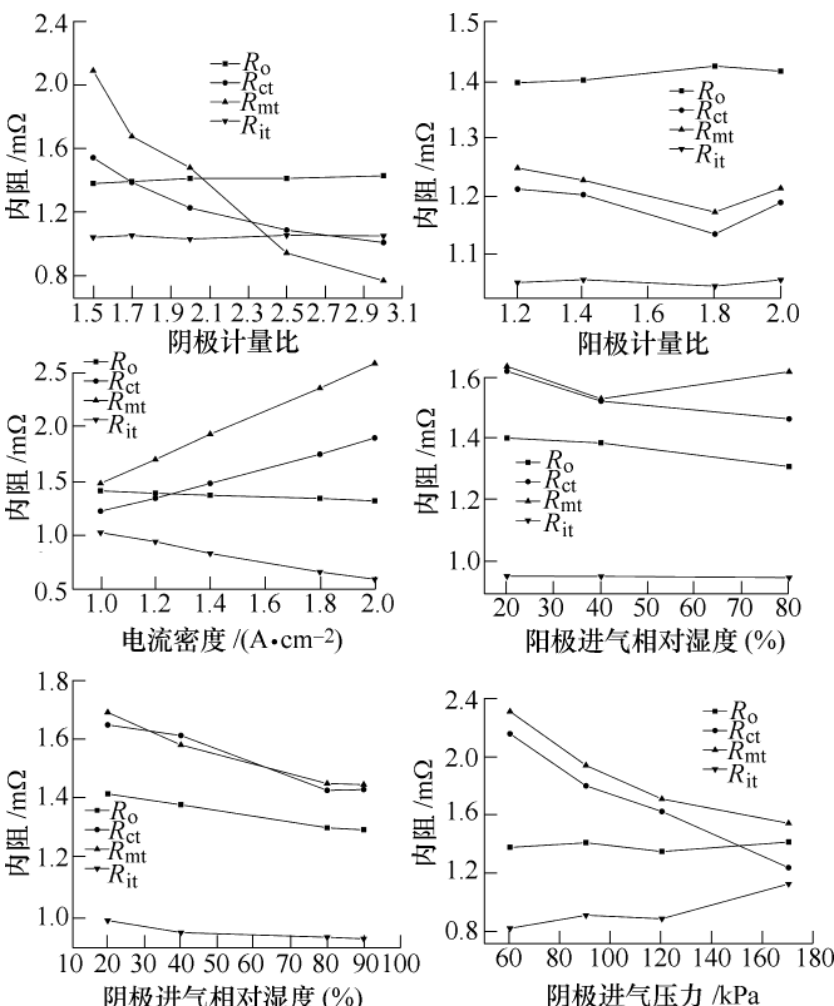

图 12 不同测试条件下等效电路模型各元件阻值

\section{4 结论}

针对试验用质子交换膜燃料电池，提出一种基 于弛豫时间分布的电化学阻抗谱分析方法, 主要结 论如下。

(1) DRT 能够将该试验电池的电化学阻抗谱分 解成 3 个不同幅值不同频率的波形 $P_{1} 、 P_{2}$ 和 $P_{3}$ 分 布，而 Nyquist 曲线只能描述两个电弧。

(2) 低频段的波形 $P_{1}$ 主要与气体扩散层和催 化剂层内氧气扩散过程有关, 中频段的波形 $P_{2}$ 主要与阴极催化剂层氧气还原反应过程有关, 中 高频段的波形 $P_{3}$ 主要与阴极侧质子传输过程 有关。

(3) $P_{1} 、 P_{2}$ 和 $P_{3}$ 均对阴极进气过量系数、进气 压力和电流密度变化较为敏感; 然而, 阴极进气湿 度对 $P_{1} 、 P_{3}$ 影响较大, 阳极进气过量系数和湿度对 所有波形影响均不大。

(4) 采用三阶等效电路模型即可描述各极化过程 阻抗大小, 且各元件阻抗值变化趋势与 DRT 分析结果 一致。

后续需要结合等效电路模型, 对如下方面展开研 究: 利用 DRT 方法分析水淹、膜干、饥饿等常见故障 的阻抗谱变化; 利用 DRT 方法分析燃料电池寿命衰退 的阻抗谱变化。 


\section{参 考 文 献}

[1] NIYA S M R, HOORFAR M. Study of proton exchange membrane fuel cells using electrochemical impedance spectroscopy technique-A review[J]. Journal of Power Sources, 2013, 240(15): 281-293.

[2] YAN X, HOU M, SUN L, et al. AC impedance characteristics of a $2 \mathrm{~kW}$ PEM fuel cell stack under different operating conditions and load changes[J]. International Journal of Hydrogen Energy, 2007, 32(17): 4358-4364.

[3] ASGHARI S, MOKMRLI A, SAMAVATI M. Study of PEM fuel cell performance by electrochemical impedance spectroscopy[J]. International Journal of Hydrogen Energy, 2010, 35(17): 9283-9290.

[4] NIYA R M, PHILlIPS R, HOORFAR M. Process modeling of the impedance characteristics of proton exchange membrane fuel cells $[\mathrm{J}]$. Electrochimica Acta, 2016, 191: 594-605.

[5] MALEVICH D, HALlioP E, PEPPLEY B, et al. Study of investigation of charge-transfer and mass-transport resistances in PEMFCs with microporous layer using electrochemical impedance spectroscopy[J]. Journal of the Electrochemical Society, 2009， 156(2): 216-224.

[6] CRUZ-MANZO S, CHEN R. An electrical circuit for performance analysis of polymer electrolyte fuel cell stacks using electrochemical impedance spectroscopy[J]. Journal of the Electrochemical Society，2013， 160(10): 1109-1115.

[7] DHIRD A M, DALE N V, SALEHFAR $\mathrm{H}$, et al. Equivalent electric circuit modeling and performance analysis of a PEM fuel cell stack using impedance spectroscopy[J]. IEEE Transactions on Energy Conversion, 2010, 25(3): 778-785.

[8] FOUQUET N, DOULET C, NOUILLANT C. Model based PEM fuel cell state-of-health monitoring via ac impedance measurements[J]. Journal of Power Sources, 2006, 159: 905-913.

[9] DANZER M A, HOFER E P. Analysis of the electrochemical behaviour of polymer electrolyte fuel cells using simple impedance models[J]. Journal of Power Sources, 2009, 190: 25-33.

[10] SCHICHLEIN H, MULLER A C, VOIGSTS M, et al. Deconvolution of electrochemical impedance spectra for the identification of electrode reaction mechanisms in solid oxide fuel cells[J]. Journal of Applied Electrochemistry, 2002, 32: 875-882.

[11] VERS-TIFFEE E, WEBER A. Evaluation of electrochemical impedance spectra by the distribution of relaxation times[J]. Journal of the Ceramic Society of Japan, 2017, 125(4): 193-201.

[12] ILLING J, ENDER M, CHROBAK T, et al. Separation of charge transfer and contact resistance in LiFePO4-cathodes by impedance modeling[J]. Journal of the Electrochemical Society, 2012，159(7): A952-A960.

[13] SCHMIDT J P, CHROBAK T, ENDER M, et al. Studies on $\mathrm{LiFePO} 4$ as cathode material using impedance spectroscopy[J]. Journal of Power Sources，2011，196: $5342-5348$.

[14] LEONIDE A, SONN V, WEBER A, et al. Evaluation and modeling of the cell resistance in anode-supported solid oxide fuel cells $[\mathrm{J}]$. Journal of the Electrochemical Society, 2008, 155(1): 36-41.

[15] WEIß A, SCHINDLER S, GALBIATI S, et al. A. distribution of relaxation times analysis of high-temperature PEM fuel cell impedance spectra[J]. Electrochimica Acta, 2017, 230: 391-398.

[16] 施王影, 贾川, 张永亮, 等. 固体氧化物燃料电池电化 学阻抗谱差异化研究方法和分解 [J]. 物理化学学报, 2019, 35(5): 509-516.

SHI Wangying, JIA Chuan, ZHANG Yongliang, et al. Differentiation and decomposition of solid oxide fuel cell electrochemical impedance spectra[J]. Acta Physico-Chimica Sinica, 2019, 35(5): 509-516.

[17] SCHÖNLEBER M, KLOTZ D, IVERS-TIFFEE E, et al. A method for improving the robustness of linear Kramers-Kronig validity tests[J]. Electrochimica Acta, 2014, 131: 20-27.

[18] HAHN M, SCHINDLER S, TRIEBS L C, et al. Optimized process parameters for a reproducible distribution of relaxation times analysis of electrochemical systems[J]. Batteries, 2019, 5: 43-64.

[19] ŽIC M, PEREVERZYEV S, SUBOTIC V, et al. Adaptive multi-parameter regularization approach to construct the distribution function of relaxation times[J]. GEM-International Journal on Geomathematics, 2020, 11: $2-25$.

[20] WAN H T, SACCOCCIO M, CHEN C, et al. Influence of the discretization methods on the distribution of relaxation times deconvolution: Implementing radial basis 
functions with DRT tools[J]. Electrochimica Acta, 2015, 184: 483-499.

[21] PIVAC I, BARBIR F. Inductive phenomena at low frequencies in impedance spectra of proton exchange membrane fuel cells-A review[J]. Journal of Power Sources, 2016, 326: 112-119.

[22] REZAEI NIYA S M, HOORFAR M. Process modeling of electrodes in proton exchange membrane fuel cells[J].
Journal of Electroanalytical Chemistry, 2015, 747 : 112-122.

作者简介: 袁浩, 男, 1999 年出生, 博士研究生。主要研究方向为燃料 电池系统建模、控制及状态估计。

E-mail: yuanhao@tongji.edu.cn 戴海峰(通信作者), 男, 1981 年出生, 博士, 教授, 博士研究生导师。 主要研究方向为汽车电子、动力电池成组及管理、燃料电池建模与控制 和车载充电机。

E-mail: tongjidai@tongji.edu.cn 